immunoglobulin (IVIg) has been attributed to blockade of the receptors on the cell surface of macrophages and monocytes for the Fc region of IgG $(F c \gamma R)$ resulting in antibody dependent cellular cytotoxicity (ADCC) inhibition. ${ }^{1}$ This is supported by the findings that IVIg slows the clearance of red cells coated with anti-D immunoglobulin and treatment with anti-D raises the platelet count in D-positive patients with immune thrombocytopenic purpura with or without a spleen. Patients with GuillainBarré syndrome or chronic inflammatory demyelinating polyneuropathy may improve after plasma exchange, infusion of fresh frozen plasma, or after treatment with IVIg. ${ }^{2}$ Monocytes and macrophages play an important part in the pathogenesis of Guillain-Barré syndrome and chronic inflammatory demyelinating polyneuropathy. ${ }^{3}$ Inflammatory cells are present in the nerves from the earliest stages of GuillainBarré syndrome. Demyelination occurs only in tissue infiltrated with inflammatory cells and degenerated myelin is largely restricted to nerve fibres invaded by macrophages. ${ }^{4}$

To investigate if blockade of $F c \gamma R$ on invading macrophages by anti-D immunoglobulin results in improvement in chronic inflammatory demyelinating polyneuropathy, anti-D immunoglobulin was given to a D-positive patient with chronic inflammatory demyelinating polyneuropathy who had never had spontaneous remissions and who in a double blind crossover study had responded to IVIg and not to albumin. Response to anti-D immunoglobulin was compared with that after IVIg.

After approval by the ethics committee of the Academic Medical Centre and with the informed consent of the patient he received $26 \mu \mathrm{g} / \mathrm{kg}$ bodyweight/day intravenously on three consecutive days (total dose $3 \mathrm{mg}$ ) of human anti-D immunoglobulin (Rhesuman Berna iv). Haemoglobin fell from 10.5 $\mathrm{mmol} / 1$ on day 1 to $7.5 \mathrm{mmol} / \mathrm{l}$ on day 8 and the packed cell volume from 0.50 to $0 \cdot 34$. Haptoglobin decreased from $1.3 \mathrm{~g} / 1$ to values below $0 \cdot 1 \mathrm{~g} / 1$ on day 3 . From day 8 onwards these values slowly increased. Bilirubin increased from $6 \mu \mathrm{mol} / 1$ to 27 $\mu \mathrm{mol} / 1$ on day 3 . The erythrocyte direct antiglobulin test became strongly positive with a titre of $1: 256$ on day 3 .

After two weeks muscle strength, electrophysiological variables, and walking distance had not changed and treatment with $0.4 \mathrm{~g} / \mathrm{kg}$ bodyweight IVIg on five consecutive days was started. Muscle strength and walking distance improved. Most changes in electrophysiological measurements were in the direction of improvement.

The non-blind design has probably not influenced the results. The patient was very much in favour of this experimental treatment because of its convenience. The results of measurements of muscle strength during the first week after anti-D immunoglobulin treatment did not differ much. Moreover, electrophysiological testing, which cannot be influenced by the patient, showed changes in the direction of deterioration rather than improvement.

The anti-D immunoglobulin dosage was not too low. The same or lower dosage is effective in patients with immune thrombocytopenic purpura and haemolysis was clearly present. Improvement after subsequent IVIg treatment was convincingly shown by the increase in walking distance from 50 to at least $1000 \mathrm{~m}$ and by the increase in muscle strength as tested with a myometer. The results of measurement at four weeks showed that most were outside the mean +2 SD of the first results and most changes in electrophysiological measurements were in the direction of improvement although this method of testing is not very sensitive shortly after improvement in patients with chronic inflammatory demyelinating polyneuropathy.

Patients with immune thrombocytopenic purpura respond to anti-D and IVIg. The response to anti-D immunoglobulin is not restricted to patients with a spleen and enhanced ADCC blocking was found in anti-D preparations in an Ig-fraction distinct from the anti-D activity. The suggestion was that this strong ADCC inhibitory activity in anti-D immunoglobulin was due to Fc-receptor blocking antibodies produced in the course of immunisation.

This patient with chronic inflammatory demyelinating polyneuropathy responded to IVIg and not to anti-D. From this finding we conclude that either improvement after IVIg in chronic inflammatory demyelinating polyneuropathy and immune thrombocytopenic purpura is based on a common mechanism but that anti-D influences a pathogenic pathway in immune thrombocytopenic purpura which is not involved in chronic inflammatory demyelinating polyneuropathy or that IVIg has a different action in the two diseases.

\section{Nitric oxide production in bacterial} meningitis

Bacterial meningitis of adults is still a pneumococcal meningitis being as high as $30 \%$. Intracranial complications such as cerebrovascular involvement, brain oedema, and increased intracranial pressure may lead to irreversible neuronal damage. ${ }^{1}$ The pathophysiological mechanisms of bacterial meningitis are still unknown in detail. Experimental studies of bacterial meningitis indicate that several mediators including cytokines, platelet activating factor, arachidonic acid metabolites, and reactive oxygen species are involved in the pathophysiology. ${ }^{2}$ Recently, we have shown that nitric oxide (NO) is involved as a mediator of cerebrovascular changes and brain oedema in the early phase of pneumococcal serious disease with the mortality from

We thank Professor Ph Rümke and Dr P Aalbersberg for the anti-D immunoglobulin (Primmed), Professor B Ongerboer de Visser for electrophysiological studies, and Dr E S Louwerse for measuring muscle strength.

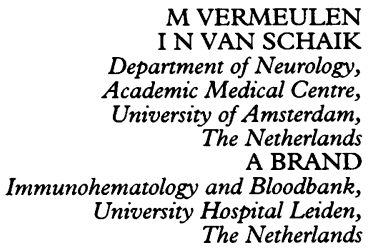

Correspondence to: Professor $M$ Vermeulen, Department of Neurology, AMC, Meibergdreef 9, 1105 AZ Amsterdam, The Netherlands.

1 Debré M, Bonnet MC, Fridman WH, et al. Infusion of $\mathrm{Fc} \gamma$ fragments for treatment of children with acute immune thrombocytopenic purpura. Lancet 1993;342:945-9.

2 Vermeulen $M$, Van der Meché FGA, Speelman JD, Weber A, Busch HFM. Plasma and gammaglobulin infusion in chronic inflammatory polyneuropathy. $\mathcal{F}$ Neurol Sci 1985;70:317-26.

3 Bansil S, Mithen FA, Singhal BS, Cook SD, Rohowsky-Kochan C. Elevated neopterin levels in Guillain-Barré syndrome. Arch levels in Guillain-Barr

4 Prineas JW. Pathology of the Guillain-Barre syndrome. Ann Neurol 1981;9(suppl):6-19.

5 Petri IB, Berek ALI. Further investigation of non-specific biological substance antiRh(D) preparations. Vox Sang 1986;51: 287-91.

meningitis in the rat. ${ }^{3}$ Nitric oxide, which is produced from L-arginine by NO-synthases (NOS) plays a part in the pathophysiology of a variety of CNS disorders including cerebral ischaemia and seizures and in inflammatory processes. ${ }^{4}$ During inflammation, large amounts of $\mathrm{NO}$ and superoxide radical are thought to be produced by polymorphonuclear leucocytes, macrophages, and blood vessels. We investigated NO production in serial CSF samples from six patients with bacterial meningitis (table). Production of NO was assessed by measuring nitrite, a stable metabolic product of NO. Nitrite determinations were made on $50 \mu \mathrm{l}$ aliquots of CSF sample mixed with $200 \mu \mathrm{l}$ of Griess reagent. The absorbance was read at $543 \mathrm{~nm}$ after 10 minutes of reaction and nitrite concentration was determined with reference to a standard curve from concentrations of $1 \mu \mathrm{M}$ to

White blood cell count (WBC) and nitrite concentration in CSF of six patients with bacterial meningitis

\begin{tabular}{|c|c|c|c|c|}
\hline $\begin{array}{l}\text { Patient } \\
\text { age/sex }\end{array}$ & $\begin{array}{l}\text { Days after } \\
\text { onset of } \\
\text { disease }\end{array}$ & $\begin{array}{l}\text { CSF WBC } \\
(\text { cells/ } / \mu l)\end{array}$ & $\begin{array}{l}\text { Bacteria cultured } \\
\text { from } C S F\end{array}$ & $\begin{array}{l}\text { CSF nitrite } \\
\text { (nmolll) }\end{array}$ \\
\hline \multirow[t]{3}{*}{$18 / F$} & 1 & 3370 & Neisseria meningitidis & 57 \\
\hline & 2 & 1953 & - & 37 \\
\hline & 4 & 163 & - & 36 \\
\hline \multirow{3}{*}{$34 / M$} & 1 & 2100 & Streptococcus pneumoniae & 85 \\
\hline & 2 & 1120 & - & 33 \\
\hline & 3 & 2730 & - & 36 \\
\hline \multirow{3}{*}{$18 / \mathrm{M}$} & 1 & 23000 & Neisseria meningitidis & 69 \\
\hline & 16 & 140 & - & 25 \\
\hline & 66 & 33 & $\bar{\pi}$ & 27 \\
\hline \multirow{2}{*}{$59 / \mathrm{F}$} & 1 & 1900 & Haemophilus influenzae & 34 \\
\hline & 5 & 61 & $\overline{0}$ & 24 \\
\hline \multirow{3}{*}{$67 / F$} & 1 & 491 & Streptococcus pneumoniae & 47 \\
\hline & 2 & $22^{\star}$ & - & 44 \\
\hline & 6 & $10^{\star}$ & $\overline{0}$ & 42 \\
\hline \multirow{3}{*}{$60 / \mathrm{M}$} & 1 & 9000 & Streptococcus bovis & 44 \\
\hline & 2 & 9813 & - & 24 \\
\hline & 4 & 336 & - & 27 \\
\hline
\end{tabular}

CSF nitrite concentrations in controls ranged from $20 \mathrm{nmol} / 1$ to $33 \mathrm{nmol} / 1$ (median: $24 \mathrm{nmol} / \mathrm{l})$. ${ }^{\star} \mathrm{CSF}$ was obtained from ventricular drainage. 
$1 \mathrm{mM}$ sodium nitrite. Immediately after lumbar puncture CSF was centrifuged and stored. All samples were investigated simultaneously. Each sample was measured twice and the mean value was calculated. Samples of CSF from seven patients with noninflammatory neurological disorders served as controls.

Compared with controls nitrite concentrations were raised in the first CSF sample of all six patients who had not received antibiotics at that time (table). In all patients the nitrite concentrations in CSF dropped after the onset of antibiotic treatment. Five patients made a complete recovery, one patient died due to septic shock (patient 5). Our data correspond with the findings published by Visser $e t$ al who found increased nitrite concentrations in the CSF of patients with meningococcal meningitis. ${ }^{5}$ Follow up investigations were not done in that study. Possible sources of NO during meningitis are bacteria, polymorphonuclear leucocytes, macrophages, neurons, and vascular smooth muscle cells. We recently showed that primary cultures of cerebral endothelial cells and astrocytes of the rat can be stimulated by pneumococci to release NO, presumably via the inducible NOS (unpublished data). Further studies are required to investigate whether nitrite concentrations in CSF are associated with the clinical course of the disease and thus could have a predictive role.

The study was supported by the Deutsche Forschungsgemeinschaft ( $\operatorname{Pf} 246 / 3-2)$.

HANS-WALTER PFISTER ANDREA BERNAT UWE KÖDEL

Department of Neurology

Institute of Clinical Chemistry

University of Munich,

Germany
Correspondence to: Professor Hans-Walter Pfister, Department of Neurology, University of Munich, Marchioninistrasse 15, 81377 Munich, Germany.

1 Pfister HW, Feiden W, Einhäupl KM. The spectrum of complications during bacteria meningitis in adults: a prospective clinical study. Arch Neurol 1993;50:575-81

2 Quagliarello VJ, Scheld WM. Bacterial meningitis. Pathogenesis, pathophysiology and progress. New Engl $f$ Med 1992;327: 864-72.

3 Haberl RL, Anneser F, Ködel U, Pfister HW. Is nitric oxide involved as a mediator of Is nitric oxide involved as a mediator of
cerebrovascular changes in the early phase cerebrovascular changes in the early phase
of experimental pneumococcal meningitis? of experimental pneumococal
Neurol Res 1994;16:108-12.

4 Moncada S, Higgs A. Mechanisms of disease: the L-arginine nitric oxide pathway. New Engl f Med 1993;329:2002-12.

5 Visser J, Scholten RJPM, Hoekman K. Nitric oxide synthesis in meningococcal meningitis. Ann Intern Med [letter] 1994;120: 345-6. 